\title{
A new furanoxanthone from Garcinia mangostana
}

\begin{abstract}
Our phytochemical study on the stem bark of Garcinia mangostana has led to the discovery of a new furanoxanthone, mangaxanthone A (1), together with five known analogs. The five known analogs that were isolated are $\alpha$-mangostin (2), $\beta$-mangostin (3), cowagarcinone B (4), and dulcisxanthone $F(5)$. The structural elucidations of these compounds were carried out by interpreting their spectroscopic data, mainly 1D and 2D NMR spectra and MS.
\end{abstract}

Keyword: Guttiferae; Garcinia mangostana; Xanthones; Furanoxanthone 